\title{
Women's Experience of Pregnancy and Birth during the Covid-19 Pandemic: A Qualitative Study
}

\author{
Niamh Keating \\ UCD Perinatal Research Centre \\ Brendan Dempsey \\ UCD Perinatal Research Centre \\ Siobhan Corcoran \\ National Maternity Hospital \\ Joan Lalor \\ Trinity College Dublin \\ Mary Higgins ( $\square$ mary.higgins@ucd.ie ) \\ UCD Perinatal Research Centre
}

\section{Research Article}

Keywords: women, pregnancy, experience, COVID

Posted Date: December 29th, 2020

DOI: https://doi.org/10.21203/rs.3.rs-124339/v1

License: (c) (1) This work is licensed under a Creative Commons Attribution 4.0 International License.

Read Full License

Version of Record: A version of this preprint was published at Irish Journal of Medical Science (1971 -) on December 2nd, 2021. See the published version at https://doi.org/10.1007/s11845-021-02862-2. 
1 Women's Experience of Pregnancy and Birth during the Covid-19 pandemic: a qualitative 2 study

3

4 Niamh E Keating ${ }^{1,2}$, Brendan Dempsey ${ }^{2}$, Siobhan Corcoran ${ }^{1}$, Joan Lalor ${ }^{3}$, Mary F Higgins ${ }^{1,2}$

5

$6{ }^{1}$ Obstetrics and Gynaecology, National Maternity Hospital, Dublin 2, Republic of Ireland 7

8 2UCD Perinatal Research Centre, National Maternity Hospital, University College Dublin,

9 Republic of Ireland

10

$11{ }^{3}$ School of Nursing and Midwifery, Trinity College Dublin

12

13

14 Author for Correspondence:

15 Mary Higgins

16 UCD Perinatal Research Centre

17 65-66 Lower Mount Street

18 Dublin 2

19 D02 YH21

20 Republic of Ireland

21 Mary.higgins@ucd.ie 
Abstract

27

BACKGROUND: The COVID-19 pandemic has changed how maternity care services are provided worldwide. In an effort to contain the virus many providers have reduced the number of face-to-face visits for women. In addition, partner attendance is now prohibited in many circumstances in order to protect staff, and other service users, from potential infection.

METHODS: A qualitative study with 14 women was conducted using a grounded theory approach. Data were collected between April to June 2020 and in-depth interviews were conducted either in pregnancy or in the first 12 weeks after the birth.

\section{RESULTS:}

Six categories emerged: loss of normality, navigating "new" maternity care systems, partners as bystanders, balancing information, uncertainty, and unexpected benefits of pregnancy during the pandemic. Women described the challenges they faced with accessing information on the risk of COVID-19 in pregnancy specifically and how to navigate the new hospital and community restrictions. For the most part women accepted many of the restrictions as they understood as being in place to keep them safe. They perceived themselves as a vulnerable group despite apparent available evidence to the contrary. The loss of the partner as an advocate, particularly at the anomaly scan and in the neonatal intensive care, was a source

47 of anxiety. Social media was the main source of information for many in place of traditional sources such as healthcare providers. Some unexpected benefits of restrictions included 
49 working from home which allowed women to manage normal pregnancy symptoms such as

50 fatigue at home.

51

52 CONCLUSION: The pandemic caused anxiety for pregnant women. This is exacerbated by

53 uncertainty about the effects of COVID-19 on pregnancy and unclear messaging about

54 restrictions. Pregnancy has a significant temporal component and so maternity services need

55 to respond to women's needs for information and support rapidly

56 and effectively, with more interactive and personalised communication to support them to

57 cope with uncertainty. The birth partner is an important role as an advocate for women.

58 Containment strategies for the pandemic should be developed with this in mind and attempt

59 to view the family as a unit rather than the woman in isolation.

60

61

62

Words: 347 of 350 permitted

63

Keywords: women, pregnancy, experience, COVID

64

65

66

67

68

69

70

71

72 
With the declaration of COVID-19 as a Public Health Emergency in January 2020(1), maternity services had to adapt quickly and change how care was provided. The time sensitive nature of provision of maternity care meant that the cancellation of services was not an option. Changes made included reduced face to face hospital visits, partners and visitors were asked not to attend routine appointments and ultrasounds, strict visiting restrictions were placed in the Neonatal Intensive Care Unit (NICU), allowing only the mother to visit infants for a limited time per day. In addition, the postnatal wards were closed to visitors including partners.

82

Early data on the COVID-19 infection in pregnancy was reassuring(2); however, initial studies were based on small numbers of cases in China and there was much uncertainty about the potential impact of the virus on pregnancy, particularly in the early stages of the pandemic. Previous coronavirus health crises due to Severe Acute Respiratory Distress Syndrome (SARS) and Middle Eastern Respiratory Distress Syndrome (MERS) were associated with significant morbidity including severe respiratory illness, increased Intensive Care Unit (ICU) admission and mortality in pregnancy(3).

90

91 This pandemic has been dubbed an "info-demic"(4) and while the H1N1 pandemic of 2009

92 was the first of the internet age, social media plays an even greater role in the rapid spread of information and at times misinformation about COVID-19. Perceived mixed messages from

94 public health officials can lead to confusion, uncertainty and fear(5). While studies have 95 shown that exposure to media or public health focused advertising during the H1N1 pandemic 
had a positive impact on health knowledge and behaviours, the impact of social media

97 platforms such as Twitter and Facebook was not fully evaluated(6).

98

99 "Lockdown" by which people were ordered to stay in their homes to reduce social contacts 100 and limit the spread of Covid -19 was a strategy adopted by many countries. Social isolation 101 can have profound effects on mental health and previous studies have identified women and 102 mothers of children under the age of 18 to be particularly vulnerable(7) . In times of disaster 103 women in the pre and postnatal period may experience higher rates of mood disorders than

104 the general public(8). Those with underlying mental health problems are at risk of post105 traumatic stress disorder(9). After the SARS health crisis an increase in avoidance behaviours, absenteeism from work and excessive hand washing was observed(10).

107 While pregnancy is a happy time for many, it can be a time of heightened anxiety and uncertainty(11). Our aim was to understand the lived experience of pregnancy during the pandemic and the effects on the women's home life and social support system as well as learn from the effects that the hospital restrictions and measures had on women and their families during extenuating circumstances. 
122 The majority of the women participating in the study were attending the National Maternity

123 Hospital which is a tertiary level unit, one of three serving the city of Dublin. Approximately 9,000 births occur within in unit every year, providing care from midwifery led to high risk multidisciplinary care.

126 The public health strategy in the management of the spread of COVID-19 in Ireland was 127 divided into stages which began with an initial containment phase in February 2020. The first 128 case of SARS-COV2 in the Republic of Ireland was detected on 29 February 2020. The World Health Organisation declared a global pandemic on the 11 th March 2020. Following this Ireland entered a delayed phase of the pandemic with the announcement of closures of schools, third level education and childcare facilities. As cases continued to rise, a "Stay at home" or "lockdown" phase was announced on 27th March with non-essential businesses closing, limitations on non-essential travel and outdoor exercise limited to within a $2 \mathrm{~km}$ radius of home. A gradual easing of restrictions was announced on 15 May. At the time of writing some restrictions have remained in place and some have been reintroduced following an increase in reported cases. At the peak of cases being reported in April and May, Ireland saw a high case fatality rate compared to many other European countries(12). This was explained by outbreaks in nursing homes and residential facilities affecting vulnerable groups. The interviews for this study were conducted between April and July 2020, therefore during the height of the first lockdown phase.

141 The aim of the study was to explore womens' the experiences of accessing maternity care

142 while pandemic related restrictions were in place. A Straussian grounded theory approach

143 was employed. The work was based a large Dublin tertiary referral unit but was open to 
144 include women from the other two Dublin maternity hospitals. These are stand-alone

145 maternity units providing a combination of consultant and midwifery lead care. Semi-

146 structured interviews were performed of women with different experiences of pregnancy

147 with sampling of groups in midwifery led care, pregnancy affected by diabetes, requirement

148 for long term admission, preterm birth, early pregnancy or postnatal women. Participants

149 were invited to participate in the study by posters and handouts in clinics, and on social

150 media. Recruitment started in April 2020 and ran until July 2020. Participants were given the

151 option of video or phone interview.

152 The interview guide (Appendix 1) based on the literature was developed by all the research

153 team members and modified as the interviews progressed allowing new hypotheses to be

154 tested. Our research team consisted of three obstetricians, one psychologist and one 155 academic midwife. None of the clinical staff interviewed women that they were directly

156 involved in caring for. As clinical members of the research team were involved in delivering

157 care during the pandemic and were involved in changes that the hospital made in order to

158 optimise that care,.

159 Data were analysed using the constant comparative method(13). Detailed notes were made

160 after each interview which allowed for interviews to be linked to analysis already performed.

161 After each interview was transcribed it was analysed which informed the development of

162 questions for the next interview. This was continued until theoretical saturation occurred.

163 One researcher (NK) reviewed all transcripts with at least one other member of the team

164 providing a second review. If discordance on categories was present, a discussion took place

165 between the researchers to reach consensus. to reduce the potential for bias it was critical

166 that the research team met after each interview was analysed in order to ensure rigor within

167 the process. 


\section{Ethical considerations}

170 Ethical approval was granted by the National Maternity Hospital Research Ethics Committee

171 and this study was carried out in accordance with their guidelines. Due to the sensitive nature

172 of the subject material, women who had experienced pregnancy loss during the pandemic

173 were not included in this study. Women were provided with written information and

174 informed consent was obtained from all participants prior to participation. All participants

175 were aged over 18 at the time of interview. In order to ensure data security, interviews were

176 carried out via secure, encrypted video conference or telephone call with digital recording.

177 Recorded data was kept on a password protected computer in a locked office. During the

178 transcription stage anonymisation was carried out by changing names and places of the data

179 to remove any potentially identifying information. Once this was carried out, audio recordings 180 were destroyed.

181

182

183

184

185

186

187

188

189

190

191 


\section{Results}

195

196

Participant characteristics

197 Sixteen women contacted the research team expressing their interest and fourteen

198 consented to participate in the study and were interviewed. Demographic information is 199 shown in Table 1, with pregnancy details in Table 2. Two women elected to be interviewed 200 over the phone with the remaining eleven interviews being carried out by recorded video conference. Three women requested copies of their interview transcripts but did not suggest any changes to be made before or during analysis.

203

Table 1. Participant Demographics

205

206

207

208

209

210

211

212

213

214

\begin{tabular}{|c|c|}
\hline Age (years) & $\mathrm{n}=$ \\
\hline $24-34$ & 4 \\
\hline $35-45$ & 10 \\
\hline Parity & \\
\hline Primipiparous & 9 \\
\hline Multipiparous & 5 \\
\hline Ethnicity & \\
\hline White Irish & 1 \\
\hline White British & 2 \\
\hline
\end{tabular}

215

216

217

218

219 
Table 2 Participant details

\begin{tabular}{|c|c|c|c|c|}
\hline $\begin{array}{l}\text { Participant } \\
\text { number }\end{array}$ & Ethnicity & $\begin{array}{l}\text { Time of } \\
\text { interview }\end{array}$ & Antenatal/postnatal & History \\
\hline 1 & $\begin{array}{l}\text { White } \\
\text { Irish }\end{array}$ & July & 3 months postnatal & P0, emergency LSCS in labour for NRCTG \\
\hline 2 & $\begin{array}{l}\text { White } \\
\text { Irish }\end{array}$ & July & 3 months postnatal & $\begin{array}{l}\text { P0, postnatal, SVD, Meconium aspiration, NICU admission for } \\
2 \text { weeks }\end{array}$ \\
\hline 3 & $\begin{array}{l}\text { White } \\
\text { Irish }\end{array}$ & July & 39 weeks & $\mathrm{P} 1$, previous SVD, interview 1 week before planned IOL \\
\hline 4 & $\begin{array}{l}\text { White } \\
\text { Irish }\end{array}$ & July & 13 weeks & $\begin{array}{l}\text { P1- previous TOP for fetal anomaly, IVF cycle cancelled due to } \\
\text { pandemic but conceived spontaneously }\end{array}$ \\
\hline 5 & $\begin{array}{l}\text { White } \\
\text { Irish }\end{array}$ & July & 3 months postnatal & Postnatal, baby underwent surgery for pyloric stenosis \\
\hline 6 & $\begin{array}{l}\text { White, } \\
\text { UK }\end{array}$ & July & 35 weeks & P0, partner is non-native English speaker \\
\hline 7 & $\begin{array}{l}\text { White } \\
\text { Irish }\end{array}$ & July & 28 weeks & P0, no medical history \\
\hline 8 & White & July & 3 months postnatal & $\begin{array}{l}\text { P1, previous difficult delivery, changed care to plan for } \\
\text { homebirth at } 37 \text { weeks due to pandemic }\end{array}$ \\
\hline 9 & $\begin{array}{l}\text { White, } \\
\text { UK }\end{array}$ & July & 28 weeks & P0, Living in Ireland for one year, private antenatal care \\
\hline 10 & $\begin{array}{l}\text { White } \\
\text { Irish }\end{array}$ & July & 8 weeks post natal & $\begin{array}{l}\text { P0, IVF pregnancy, severe PGP, SVD, private consultant lead } \\
\text { care }\end{array}$ \\
\hline 11 & $\begin{array}{l}\text { White } \\
\text { Irish }\end{array}$ & April & 34 weeks & P0, same sex couple, IVF pregnancy \\
\hline 12 & $\begin{array}{l}\text { White } \\
\text { Irish }\end{array}$ & May & 21 weeks & P0, Clomid pregnancy, interview before anatomy \\
\hline
\end{tabular}




\begin{tabular}{|l|l|l|l|l|}
\hline 13 & White & June & 2 weeks postnatal & Hx pre-term delivery, cervical cerclage at 14/40 delivered by \\
& Irish & & SVD at term \\
\hline 14 & White & May & 31 weeks & P0, gestational diabetes mellitus \\
& Irish & & & \\
\hline
\end{tabular}

Six categories were identified; loss of normality, navigating "new" maternity care systems, partners as bystanders, balancing information, uncertainty, and unexpected benefits of pregnancy during the pandemic. These are described in further detail below.

\section{Loss of normality}

Women described the "new normal" of a pregnancy during a pandemic; "it was different after the Covid stuff hit". The usual social element of pregnancy was gone as events such as baby showers were cancelled. Women found it difficult to engage with other pregnant women which added to a sense of isolation and there was less excitement surrounding the pregnancy . One women said "It would have been nice to meet other mums who were due their baby at the same time. So all that social element was totally gone"[P10]

236 The usual celebration of pregnancies with friends and family members was no longer possible

237 due to restrictions. Women felt that they missed out on sharing their pregnancy with their

238 family. This was especially difficult for women who had experienced fertility problems.

239 Women described the impact on their families who were not able to see women and had to 240 join their pregnancy through technology or seeing them through a glass window as a way of 241 involving them in their pregnancy, with one woman in her first pregnancy describing how "every week my family are like "aw send us a picture of your bump"” P12 
243 This was an isolating time for many women as they were cut off from their usual support

244 systems. One woman described the change to her visits to the antenatal clinic which became an unpleasant experience. She felt women were nearly afraid to engage in conversation with each other due to the threat of the virus, saying " in the waiting room there was always a lovely atmosphere, it was gone after the Covid stuff hit" P10

Navigating "new" Maternity Care Systems " you were made to feel there was nothing weird going on outside the doors"

Women had varying experiences of the changes in how care was delivered. One woman felt safe coming to a stand-alone maternity hospital as it felt removed from the pandemic which she associated with general hospitals. Some women had virtual or telephone consults which they felt de-personalised the experience with one woman describing a phone consultation with her obstetrician at 16 weeks as "tokenistic". Face to face antenatal visits were limited out to allow for reduced clinic size and social distancing in waiting rooms. One woman found this increased her anxiety, as being in her first pregnancy, she felt she needed the reassurance of a hospital visit.

Many hospitals changed to provide antenatal classes online. This was either pre-recorded or virtual. One woman felt that doing pre-recorded classes took away from the experience as it was less individualised, "You can't interact and you can't ask anyone" Participant 11 home birth at an advanced gestation due to fears about how the hospital would manage a potential outbreak, saying "Suddenly the risks of the home birth became less than having to spend time in [hospital]" P8 
267 The three women who did experience hospital birth during the pandemic felt that the birth

268 experience itself was not negatively impacted by the restrictions, with one participant describing the delivery room saying "I don't think there was any change in the room, the midwives, anything like that. I didn't feel I had any less care" P2

271 Some hospitals expanded early transfer home services to reduce the capacity on the postnatal

272 ward which women found beneficial, "I just find that was much better in a home setting than

273 in the hospital setting when there's so much going on" P1

274 One participant was directly affected by restrictions in NICU when her baby was unexpectedly 275 admitted with Meconium aspiration. For two weeks she was limited to spending 15 minutes every day with her baby. Her partner was not permitted in to the NICU which added to the

277 stress of having an unwell baby, "I didn't feel like his mother... my whole day was spent waiting for that 15 minutes" P2

Not having the baby's father present in the NICU added to concerns about how he would bond with the infant but also the mother felt more isolated without the support of her partner as an advocate or someone to ask questions on her behalf , "I would have benefitted hugely from having him being able to go to the NICU... He would have asked questions" P2

Partners as bystanders- "he..felt very disconnected from the whole process"

One of the most distressing aspects of the change in care during the pandemic was the restrictions on partners attending hospital visits. Anatomy scans were a particularly difficult milestone for the partners to miss out on, especially for couples who had experienced pregnancy loss previously. One woman described attending out of hours with reduced fetal 
really strange.. I had to go in on my own.. and ..I was worried that something had happened

291 to him [baby] and I had to go and sit in the waiting room by myself" P1

While none of the hospitals prevented partners from attending the birth of their children, the potential that tighter restrictions on partners caused a lot of anxiety. Women feared losing their birth partner as an advocate while they were in labour and after the birth, "I didn't experience the not having your partner there.. but my god it just terrifies me, the idea that I wouldn't have anybody that was on my side who knew me while being so very vulnerable which you are in labour" P8

Women described that by missing out on appointments he/she felt disconnected from the process "it was a team effort and I felt that had been taken away by having to go to the appointments.. by myself" P10

One women pointed out that partners were labelled as "visitors" when they should have been given special status, "It's this whole thing of... seeing partners as visitors as opposed to partners" Participant 6. Many women could not understand the restrictions placed on partners attending when they were often from the same household and felt they should have been viewed as family unit rather than individuals as "chances are your birth partner is a member of your household" P3

\section{Balancing information "the reality is it's so new I don't think people know"}

309 Many women felt that by keeping informed they would feel empowered but also appreciated that having too much access to news could feel overwhelming. The sources of information ranged from mainstream news and social media to peer reviewed medical journals. The lack

312 of up to date pregnancy specific information about the virus and its potential impact on pregnancy was a source of anxiety, "the reality is it's so new I don't think people know". 
314 Women also feared for the health of their babies and also how they would manage to care

315 for other children if they were to become unwell. Two of the women from the UK relied on

316 the Royal College of Obstetrics and Gynaecology (RCOG) for up to date and reliable pregnancy

317 information. Of note there was no Irish equivalent as a single source for patient focused

318 pregnancy specific guidance. Women looked at hospital websites but this was often not their

319 primary source of information. The lack of relevant information meant that women were less

320 likely to trust their healthcare providers as a source as they realised that the medical

321 community was uncertain about the effects of SARS-COV2 in pregnancy, "Initially they were

322 saying 'no pregnant women aren't any more high risk than anybody else' but then.. the HSE

323 are saying to their own pregnant staff 'you shouldn't be working near coronavirus patients'"

$324 P 11$

325

326 Conflicting information was a source of anxiety for women, "I'm getting different messages"

$327 \quad P 4$

328

329 Some of the messaging and language used around restrictions by the hospitals were unclear

330 which caused stress amongst women, especially when information related to when their

331 partners would be able to attend with them to hospital, with one women saying "the phrasing

332 used was.. your birth partner will be allowed in when you're in active labour... like what does

333 that mean?" P10

334

335 Uncertainty "I acted as though I was a vulnerable person"

336 
337 Women received conflicting information about the potential impact of the virus on their

338 health. Many women felt vulnerable and chose to cocoon despite the HSE recommendation

339 that this was not necessary with one women saying "We didn't have symptoms. We were

340 just pregnant, but we didn't have asthma ... or cystic fibrosis. We were just pregnant women.

341 And we were thinking, okay, so, [can] I still go on the Dart [commuter railway network] or

342 will I still go on the bus? " P11

343

344 While the initial "lockdown" message was clear, the gradual easing of restrictions brought

345 new challenges, "It's harder to know the right thing to do is... what is being responsible, what

346 is being paranoid" $P 9$

347

348 Unexpected benefits "It was a bit of a blessing in disguise"

349

350

Many of the participants highlighted unexpected benefits of the restrictions. Lockdown gave

many women the opportunity to work from home which made it easier to manage normal

352

pregnancy symptoms such as fatigue or nausea. The lack of commuting was seen as positive

353

and many women felt they had more time to devote to exercise or to spend with their

354

partners. This was also valuable after the birth as many women felt this extra time allowed

355

for bonding and there was no pressure to see people or bring their new baby out.

356

357

"We brought him home and my plan was to ..lock the door, stay in... We definitely benefitted 
“...not being overwhelmed with visitors. I'm quite glad that we can kind of have an excuse to

361 say to people 'actually, not at the moment' " $P 9$

362

363 Many women's partners were able to continue working from home after the birth which

364 allowed for additional support in the "fourth trimester".

365

366 The changes in the maternity care service had some benefits. Many women appreciated

367 quieter waiting rooms and benefitted from more community based care including early

368 transfer home teams. One woman described the positive milestones in her pregnancy which

369 gave her something to look forward to or a positive focus in uncertain times

370

371 "I think.. one of the advantages to being pregnant.. is that you... feel like there's an end to it...

372 psychological end... my family and friends are like it's groundhog day and I'm like no it's not

373 because l've got a new milestone every week or a new thing to look forward to .. so that kind

374 of helps" P9

375

376

377

378

379

380

381

382

383 


\section{Discussion}

The disruption and uncertainty that came with the pandemic at a time when women were feeling particularly vulnerable caused great anxiety. While understandably a lot of initial research into COVID-19 in pregnancy was on the physical effects, we are beginning to see the psychological effects that isolation and prolonged restrictions is having on pre and postnatal depression(14). In one study of perinatal anxiety, $60 \%$ of women reported moderate or severe anxiety symptoms(15). In a study in Italy, which was the epicentre of the pandemic in Europe in the early stages, women with a history of anxiety or depression were at a higher risk of anxiety symptoms or post-traumatic stress disorder during "lockdown" than those without(16).

Most women sought information as a coping strategy. Often this information came from social media or their peers rather that from the hospital itself. When the government in Ireland advised groups considered at risk to "cocoon", pregnant women were not included on this list, but they were in the UK; this caused confusion. In a study in China, $90 \%$ of women questioned considered themselves vulnerable(17). A perceived risk of spread of infection from birth and through breastfeeding lead to increased requests for planned Caesarean birth 403 and higher rates of bottle feeding(17). While there was no associated between information source and level of anxiety, we know that conflicting information in times of humanitarian crises is associated with higher levels of stress(18). The adverse effects of maternal stress on the fetus and on infant cognitive development are well documented(19-21). 
407 One of the strategies adopted by maternity hospitals was to introduce less frequent antenatal

408 appointments and move some consultations to telephone consultation. While there is a role 409 for developing telemedicine it is important not to depersonalise care. There is a need for 410 enhanced online support(17) and greater investment to make use of available technologies

411 to enhance the antenatal experience for women.

412

413 The women in this study relied on their partners for emotional support. The perceived risk

414 that a birth partner would not be present for delivery was a huge source of anxiety. The 415 presence of a supportive birth partner is associated with favourable birth outcomes(22).

416 The World Health Organisation (WHO) have upheld that all pregnant women should have a

417 companion of their choice present during birth(23). In one study of the effects of COVID-19

418 on women's birth expectations, women with a history of mental health disorders expressed

419 greater concern for their partner's health highlighting the important role a partner can have 420 during the pregnancy, birth and postnatal period(24).

421 The strength of this study in the in depth interviews which took place at the height of restrictions, offering a unique perspective on pregnancy in the pandemic. This study is limited by the lack of ethnic diversity in the group interviewed and further research is needed on the

424 impact of the pandemic on minority groups.

425

426

427

428

429

430 
Conclusion

435 While differences in hospital infrastructure across the maternity units in Ireland means that each hospital has had to individualise its approach to keep its patients safe in the pandemic,

437 there needs to be a clear unifying message so women do not lose faith in the service. This should take the form of clear guidance for patients and their families from a professional body such as the Royal College of Physicians in Ireland. Hospitals must be quick to embrace technology as a way of getting clear messages across.

441

442 In reducing the number of visits a woman had to make to the hospital, the maternity care service needs to replace this with interactive communication to ensure that women do not feel abandoned by the service. While telemedicine is an appropriate alternative in some settings, the "hands on " physical care required in pregnancy cannot be replaced and must be

446 adapted in future to ensure that the focus of the maternity service continues to focus 447 primarily on the women it serves and the virus second. Any public health measures taken in 448 maternity services must be mindful of the important role the birth partner can play as an emotional support person and advocate.

451 Going forward there is an opportunity to expand on community delivered care, particularly

452 for low risk women. There is an urgent need to improve mental health support to deal with 453 the potential long term sequelae this pandemic will have on our most vulnerable in society. 
455

456

457

458 
459 Abbreviations:

461 IVF (in vitro fertilisation) LSCS (lower segment caesarean section), NRCTG (non reassuring

462 cardiotocograph), NICU (neonatal intensive care unit) PO (primipaous woman); PGP (pelvic girdle pain))

463 SVD (spontaneous vaginal delivery) TOP (termination of pregnancy)

464

465 Declarations

466 Ethics approval and consent to participate

467 This study was approved by the National Maternity Hospital Ethics Committee EC 14.2020

468

469 Consent for publication not applicable

470

471 Availability of data and materials

472 The anonymised qualitative data set, analysed during the current study, is available from the 473 corresponding author upon reasonable request.

474

475 Competing interests

476 The authors declare that they have no competing interests

477

$478 \quad$ Funding

479 Unfunded

480

481

482

483

484

485 
487 NK has made a substantial contribution to the conception and design of the work. The acquisition analysis and interpretation of the data, has drafted the work and has approved the submitted version and agrees to be both personally accountable for her contribution and to ensure that questions related to the accuracy and integrity of any part of the work even ones in which the author was not personally involved are appropriately investigated, resolved and the resolution is documented in the literature.

BD has made a substantial contribution to the conception of the work, to the interpretation of the data, has substantially revised it and has approved the submitted version and agrees to be both personally accountable for his contribution and to ensure that questions related to the accuracy and integrity of any part of the work even ones in which the author was not personally involved are appropriately investigated, resolved and the resolution is documented in the literature.

SC has made a substantial contribution to the conception of the work, to the interpretation of the data, has substantially revised it and has approved the submitted version and agrees to be both personally accountable for her contribution and to ensure that questions related to the accuracy and integrity of any part of the work even ones in which the author was not personally involved are appropriately investigated, resolved and the resolution is documented in the literature.

505

JL has made a substantial contribution to the conception and design of the work, to the interpretation

507 of the data, has substantially revised it and has approved the submitted version and agrees to be both

508 personally accountable for her contribution and to ensure that questions related to the accuracy and integrity of any part of the work even ones in which the author was not personally involved are appropriately investigated, resolved and the resolution is documented in the literature. 
512 MFH has made a substantial contribution to the conception and design of the work. The acquisition

513 analysis and interpretation of the data, has drafted the work and has approved the submitted version

514 and agrees to be both personally accountable for her contribution and to ensure that questions

515 related to the accuracy and integrity of any part of the work even ones in which the author was not

516 personally involved are appropriately investigated, resolved and the resolution is documented in the

517 literature.

518

519 Acknowledgments

520 We wish to acknowledge the women who contributed to this study

521

522

523

524

525

526

527

528

529

530

531

532

533

534

535

536

537 
540 1. WHO. Statement on the second meeting of the International Health Regulations

541 (2005) Emergency Committee regarding the outbreak of novel coronavirus (2019-nCoV)

5422020 [Available from: https://www.who.int/news/item/30-01-2020-statement-on-the-

543 second-meeting-of-the-international-health-regulations-(2005)-emergency-committee-

544 regarding-the-outbreak-of-novel-coronavirus-(2019-ncov). Accessed Dec $3^{\text {rd }} 2020$

545 2. Liu Y, Chen H, Tang K, Guo Y. Clinical manifestations and outcome of SARS-CoV-2 546 infection during pregnancy. J Infect. 2020.

547 3. Schwartz DA, Graham AL. Potential Maternal and Infant Outcomes from (Wuhan)

548 Coronavirus 2019-nCoV Infecting Pregnant Women: Lessons from SARS, MERS, and Other

549 Human Coronavirus Infections. Viruses. 2020;12(2).

550 4. Zarocostas J. How to fight an infodemic. Lancet. 2020;395(10225):676.

551 5. Han PKJ, Zikmund-Fisher BJ, Duarte CW, Knaus M, Black A, Scherer AM, et al.

552 Communication of Scientific Uncertainty about a Novel Pandemic Health Threat: Ambiguity

553 Aversion and Its Mechanisms. J Health Commun. 2018;23(5):435-44.

554 6. Lin L, Savoia E, Agboola F, Viswanath K. What have we learned about communication

555 inequalities during the H1N1 pandemic: a systematic review of the literature. BMC Public

556 Health. 2014;14:484.

557 7. Perrin PC, McCabe OL, Everly GS, Jr., Links JM. Preparing for an influenza pandemic:

558 mental health considerations. Prehosp Disaster Med. 2009;24(3):223-30.

559 8. Harville E. Disasters and perinatal health : a systematic review. Obstet Gynecol Surv. $560 \quad 2010 ; 65: 713-28$.

561 9. Goodman LA, Salyers MP, Mueser KT, Rosenberg SD, Swartz M, Essock SM, et al.

562 Recent victimization in women and men with severe mental illness: prevalence and 563 correlates. J Trauma Stress. 2001;14(4):615-32.

564 10. Marjanovic Z, Greenglass ER, Coffey S. The relevance of psychosocial variables and 565 working conditions in predicting nurses' coping strategies during the SARS crisis: an online 566 questionnaire survey. Int J Nurs Stud. 2007;44(6):991-8.

567 11. Biaggi A, Conroy S, Pawlby S, Pariante CM. Identifying the women at risk of antenatal 568 anxiety and depression: A systematic review. J Affect Disord. 2016;191:62-77.

569 12. Rachel Lavin SM. Ireland's Covid-19 excess deaths higher than EU norm: Business 570 Post; 2020 [Available from: https://www.businesspost.ie/health/irelands-covid-19-excess571 deaths-higher-than-eu-norm-7995a4be. Accessed Dec $3^{\text {rd }} 2020$

572 13. Glaser B. Theoretical Sensitivity. Advances in the Methodology of Grounded Theory. 5731978.

574 14. Berthelot N, Lemieux R, Garon-Bissonnette J, Drouin-Maziade C, Martel É, Maziade

575 M. Uptrend in distress and psychiatric symptomatology in pregnant women during the 576 coronavirus disease 2019 pandemic. Acta Obstet Gynecol Scand. 2020;99(7):848-55.

577 15. Farewell CV, Jewell J, Walls J, Leiferman JA. A Mixed-Methods Pilot Study of Perinatal 578 Risk and Resilience During COVID-19. J Prim Care Community Health.

579 2020;11:2150132720944074.

580 16. Ravaldi C, Ricca V, Wilson A, Homer C, Vannacci A. Previous psychopathology 581 predicted severe COVID-19 concern, anxiety, and PTSD symptoms in pregnant women 582 during "lockdown" in Italy. Arch Womens Ment Health. 2020. 
17. Liu X, Chen M, Wang Y, Sun L, Zhang J, Shi Y, et al. Prenatal anxiety and obstetric

584 decisions among pregnant women in Wuhan and Chongqing during the COVID-19 outbreak:

585 a cross-sectional study. Bjog. 2020;127(10):1229-40.

586 18. Purgato M, Gastaldon C, Papola D, van Ommeren M, Barbui C, Tol WA. Psychological 587 therapies for the treatment of mental disorders in low- and middle-income countries

588 affected by humanitarian crises. Cochrane Database Syst Rev. 2018;7:CD011849.

589 19. Wu Y, Lu YC, Jacobs M, Pradhan S, Kapse K, Zhao L, et al. Association of Prenatal

590 Maternal Psychological Distress With Fetal Brain Growth, Metabolism, and Cortical

591 Maturation. JAMA Netw Open. 2020;3(1):e1919940.

592 20. Madigan S, Oatley H, Racine N, Fearon RMP, Schumacher L, Akbari E, et al. A Meta-

593 Analysis of Maternal Prenatal Depression and Anxiety on Child Socioemotional

594 Development. J Am Acad Child Adolesc Psychiatry. 2018;57(9):645-57 e8.

595 21. Tarabulsy GM, Pearson J, Vaillancourt-Morel MP, Bussieres EL, Madigan S, Lemelin

$596 \mathrm{JP}$, et al. Meta-analytic findings of the relation between maternal prenatal stress and anxiety

597 and child cognitive outcome. J Dev Behav Pediatr. 2014;35(1):38-43.

598 22. Bohren MA, Hofmeyr GJ, Sakala C, Fukuzawa RK, Cuthbert A. Continuous support for 599 women during childbirth. Cochrane Database of Systematic Reviews. 2017(7).

600 23. World Health Organisation. Coronavirus disease (COVID-19): Pregnancy and

601 childbirth 2020 [Available from: https://www.who.int/news-room/q-a-detail/coronavirus-

602 disease-covid-19-pregnancy-and-childbirth. Accesssed Dec $3^{\text {rd }} 2020$

603 24. Ravaldi C, Wilson A, Ricca V, Homer C, Vannacci A. Pregnant women voice their

604 concerns and birth expectations during the COVID-19 pandemic in Italy. Women Birth. 2020. 